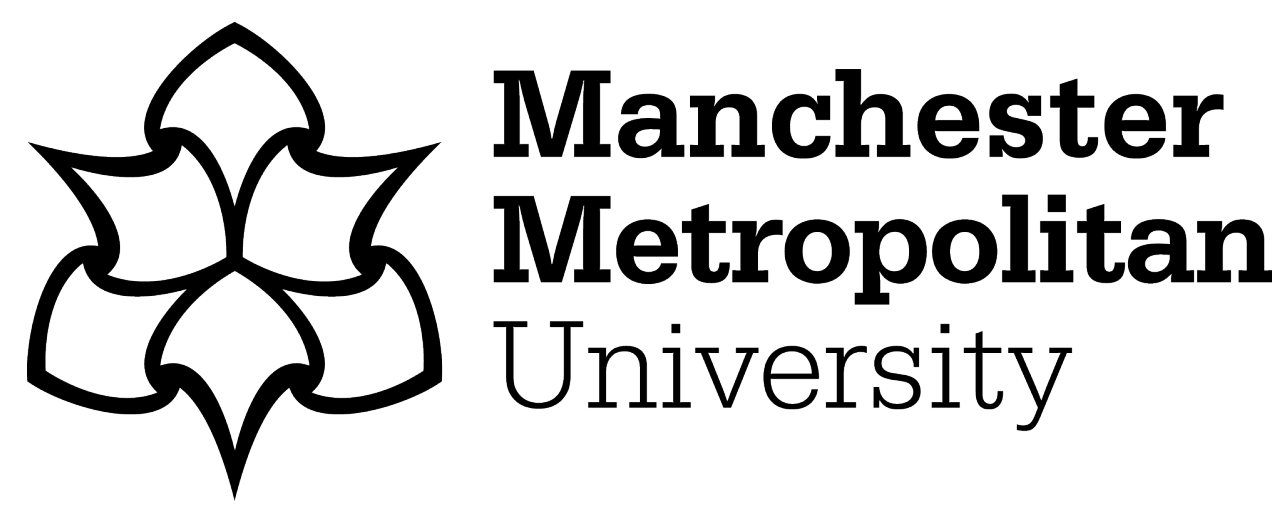

Dobbin, Nick, Hunwicks, Richard, Jones, Ben, Till, Kevin, Highton, Jamie and Twist, Craig (2018) Criterion and Construct Validity of an Isometric Midthigh-Pull Dynamometer for Assessing Whole-Body Strength in Professional Rugby League Players. International Journal of Sports Physiology and Performance, 13 (2). pp. 235-239. ISSN 1555-0265

Downloaded from: https://e-space.mmu.ac.uk/621563/

Version: Accepted Version

Publisher: Human Kinetics

DOI: https://doi.org/10.1123/ijspp.2017-0166

Please cite the published version 


\title{
Criterion and Construct Validity of an Isometric Midthigh-Pull Dynamometer for Assessing Whole-Body Strength in Professional Rugby League Players
}

\author{
Nick Dobbin, Richard Hunwicks, Ben Jones, Kevin Till, Jamie Highton, and Craig Twist
}

\begin{abstract}
Purpose: To examine the criterion and construct validity of an isometric midthigh-pull dynamometer to assess whole-body strength in professional rugby league players. Methods: Fifty-six male rugby league players (33 senior and 23 youth players) performed 4 isometric midthigh-pull efforts (ie, 2 on the dynamometer and 2 on the force platform) in a randomized and counterbalanced order. Results: Isometric peak force was underestimated $(P<.05)$ using the dynamometer compared with the force platform $(95 \% \mathrm{LoA}:-213.5 \pm 342.6 \mathrm{~N})$. Linear regression showed that peak force derived from the dynamometer explained $85 \%$ (adjusted $R^{2}=.85, \mathrm{SEE}=173 \mathrm{~N}$ ) of the variance in the dependent variable, with the following prediction equation derived: predicted peak force $=[1.046 \times$ dynamometer peak force $]+117.594$. Cross-validation revealed a nonsignificant bias $(P>.05)$ between the predicted and peak force from the force platform and an adjusted $R^{2}(79.6 \%)$ that represented shrinkage of $0.4 \%$ relative to the cross-validation model $(80 \%)$. Peak force was greater for the senior than the youth professionals using the dynamometer $(2261.2 \pm 222 \mathrm{cf} 1725.1 \pm 298.0 \mathrm{~N}$, respectively; $P<.05)$. Conclusion: The isometric midthigh pull assessed using a dynamometer underestimates criterion peak force but is capable of distinguishing muscle-function characteristics between professional rugby league players of different standards.
\end{abstract}

Keywords: peak force, measurement error, talent identification, collision sport, evaluation

Maximum muscle strength is an important physical quality for rugby league that is related to fundamental performance characteristics (eg sprint performance, tackling ability $)^{1-3}$ and is associated with a lower risk of injury. ${ }^{4}$ Maximal strength is also known to differentiate between playing standard, ${ }^{5-7}$ meaning it has importance as part of talent identification. Practitioners must therefore be able to accurately assess a rugby league player's whole-body maximal strength.

The assessment of maximal strength using isoinertial measures (eg 1-repetition-maximum squat) is traditionally used in rugby league ${ }^{1,5,6,8}$ but can be influenced by individual technique and experience. ${ }^{9}$ Isoinertial dynamometry is also associated with an increased risk of injury, ${ }^{10}$ while testing with large squads can be time-consuming. Taken together, the shortcomings of isoinertial dynamometry suggest that practitioners should think carefully about the selection of a valid, safe, and time-efficient measure of maximal strength.

The use of the isometric midthigh pull offers a method of maximal-strength assessment that meets the aforementioned criteria. ${ }^{11-13}$ The midthigh pull requires participants to stand on a force platform with an immovable bar positioned to correspond with the second-pull clean position, just below the crease of the hip. ${ }^{14}$ Participants are then instructed to pull as fast and hard as possible, enabling various kinetic measures to be quantified from groundreaction forces. ${ }^{15,16}$ With good reliability ${ }^{14,17,18}$ and strong relationships with dynamic actions such as sprinting and jumping, ${ }^{3,16}$ the isometric midthigh pull presents a useful method for assessing

Dobbin, Highton, and Twist are with the Dept of Sport and Exercise Sciences, University of Chester, Chester, United Kingdom. Hunwicks is with Rugby Football League, Leeds, United Kingdom. Till and Jones are with the Inst for Sport, Physical Activity and Leisure, Leeds Beckett University, Leeds, United Kingdom. Twist (c.twist@chester.ac.uk) is corresponding author. whole-body maximum strength. However, the utility of the method is likely to be limited by the availability of a force platform. ${ }^{16}$

The development of a custom-built isometric midthigh-pull dynamometer offers a more cost-effective method for the safeand time-efficient measure of maximal strength. However, for practitioners it is important to understand the validity of any new device against the criterion method, ${ }^{19}$ while it must be capable of differentiating between those of different training status (ie, construct validity).$^{20}$ In a recent study by James et al, ${ }^{18}$ isometric midthigh-pull performance measured using a strain gauge had good reliability (coefficient of variation $=3.1 \%$ ) but poor criterion validity when compared against the same exercise conducted on a force platform. In that study, validity was assessed using a relatively small sample size of recreationally active participants $(\mathrm{N}=15)$ and no attempt was made to understand the ability of the simplified apparatus to differentiate peak-force capabilities between athletes of different training status (ie, construct validity). Accordingly, the purpose of this study was twofold: to compare the peak forces obtained in a group of professional rugby league players during the isometric midthigh pull between a custom-built dynamometer and a force platform (ie, criterion validity) and to establish the utility of the isometric midthigh pull to differentiate muscle-strength characteristics between rugby league players of different standards (ie, construct validity).

\section{Methods}

\section{Participants and Design}

With institutional ethics approval and participant consent, 56 male rugby league players were recruited from 2 professional clubs and classified as senior professional $(n=33$, age $25.3 \pm 3.4 \mathrm{y}$, stature $183.9 \pm 6.8 \mathrm{~cm}$, body mass $97.9 \pm 9.5 \mathrm{~kg}$ ) and youth professional $(\mathrm{n}=23$, age $18.3 \pm 1.4 \mathrm{y}$, stature $179.2 \pm 5.2 \mathrm{~cm}$, body 
mass $86.2 \pm 8.2 \mathrm{~kg}$ ) players. Senior players had completed at least 1 season training for and competed in Super League competition. Youth consisted of players who were currently playing at academy standard or who had in the last 3 months graduated to the first team. Data were collected in the preseason period, with all players having at least 2 years of systematic resistance-training experience that involved lower-body maximum lifts. After habituation, each player completed 2 isometric midthigh-pull strength assessments on the dynamometer and force platform in a randomized crossover design with a 5-minute passive recovery between efforts. All testing was carried out indoors on a hard, nonslip surface.

\section{Methods}

All participants completed a standardized warm-up before the midthigh pull that comprised 5 minutes of dynamic stretching along with 2 isometric efforts at $50 \%$ and $75 \%$ of maximal effort. ${ }^{21}$ For both measurements, participants were positioned similar to the second-pull phase of the power clean, with the bar located midway between the knees and hips, knees flexed at $\sim 140^{\circ}$, and shoulders over the bar. ${ }^{22}$ Based on previous literature, participants were given a 3-second countdown and instructed to pull as fast and hard as possible for 5 seconds, placing emphasis on the rate of force development, which is reported to aid maximal-force development. ${ }^{23}$

Dynamometer. A custom-built isometric midthigh-pull dynamometer was designed and built to include a T.K.K.5402 dynamometer (Takei Scientific Instruments Co Ltd, Niigata, Japan) sampling at $122 \mathrm{~Hz}$. Briefly, this consisted of a wooden platform $(80 \times 50 \mathrm{~cm})$ with rubber foot grips $(31 \times 20 \mathrm{~cm})$ placed shoulder width apart and a chain $(51 \mathrm{~cm})$ from the dynamometer to a latissimus pulldown bar $(120 \mathrm{~cm}$; Decathlon, United Kingdom; see Figure $1[\mathrm{~B}])$. The chain length was adjusted to allow participants to achieve the described position. Before pulling, participants applied minimal pretension to the chain to avoid any jerking action on initiating the lift. The highest peak force from the 2 attempts was then multiplied by 9.81 (to represent the value in Newtons) and subsequently used for analysis.

Force Platform. The isometric midthigh pull was performed using a commercially available portable force platform (HUR Labs, FP4, Tampere, Finland) with a sampling rate of $1200 \mathrm{~Hz}$. The force plate

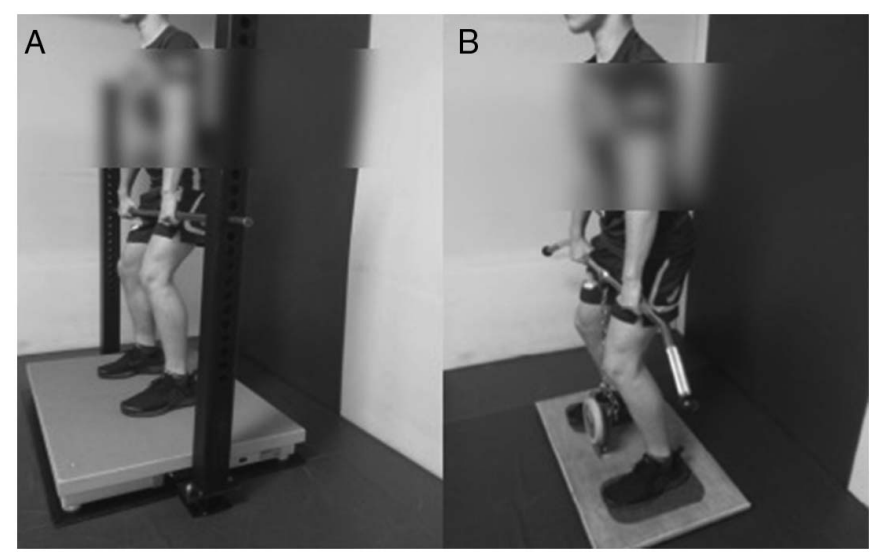

Figure 1 - Isometric midthigh pull performed on (A) a force platform and (B) a modified dynamometer. was seated in a customized fixed rack, which enabled adjustments in bar height by $3-\mathrm{cm}$ increments (Figure 1[A]). Where necessary, smaller adjustments in bar height were made by placing $1-\mathrm{cm}$ wooden boards on the force platform. In such instances the force platform was then recalibrated before any measurement was performed. Each participant's best trial from 2 attempts, as determined by the highest peak force (PF) in Newtons, was used for analysis. ${ }^{21}$

\section{Statistical Analyses}

Data were initially checked for normality via the Shapiro-Wilk statistic $(P>.05)$ before using Pearson product-moment correlations ( $r$ value) to check for heteroscedastic errors and assess the relationship between methods. Paired-sample $t$ tests were used to calculate differences (biases) between means of measurement methods (criterion validity) and followed up using 95\% limits of agreement $(95 \% \mathrm{LoA})^{24}$ to quantify the within-subject variation (random error). Effect sizes (ES) and 90\% confidence intervals (CI [lower bound-upper bound]) were also used to quantify the magnitude of the effect between methods and groups using the following criteria: $0.2,0.6$, and 1.2 for small, moderate, and large effects, respectively. ${ }^{25}$ Linear-regression analysis was used to determine a prediction equation for peak force along with the typical regression statistics ( $R^{2}$ and SEE). Using an $80 / 20 \%$ split of the sample, ${ }^{26}$ we cross-validated the prediction equation and sought to establish that there was minimal shrinkage in the $R^{2}$ value relative to the model. This being the case, the full predictive model can be presented. To determine the sensitivity of the isometric midthigh pull against an analytical goal, an independent $t$ test was used to assess between-groups differences in PF (construct validity) and normalized $\mathrm{PF}$ using ratio $(\mathrm{PF} / \mathrm{BM})$ and allometric $\left(\mathrm{PF} / \mathrm{BM}^{b}\right)$ scaling, where $\mathrm{PF}=$ peak force, $\mathrm{BM}=$ body mass in kilograms, and $b=$ a power exponent. ${ }^{27}$ Within-session reliability was determined using coefficient of variation $(\mathrm{CV})$ and intraclass correlation coefficient (ICC). Data are reported as mean and SD and analyzed using SPSS for Windows (Version 23.0, 2015) and a predesigned spreadsheet. ${ }^{28}$

\section{Results}

Within-session reliability revealed CVs of $8.3 \%$ and $9.2 \%$ and ICCs of .913 and .912 for the dynamometer and force platform, respectively.

Isometric PF was significantly underestimated $(P<.001, \mathrm{ES}=$ $-0.53[-0.85$ to -0.21$])$ using the dynamometer compared with the force platform, with $95 \%$ of the differences ranging between -556.1 and $130.1 \mathrm{~N}$. However, there was a strong, significant relationship for $\mathrm{PF}$ between the dynamometer and force platform $(r=.92, P<.001)$ (Table 1, Figure 2).

The regression analysis based on the cross-validation sample (Table 2) revealed that PF derived from the dynamometer explained $80 \%$ (adjusted $R^{2}=.80$ ) of the variance in the dependent variable, yielding the equation predicted $\mathrm{PF}(\mathrm{N})=(1.046 \times$ dynamometer PF $)+117.594$. Cross-validation analysis revealed no significant difference $(P=.724, \mathrm{ES}=0.05[-0.26$ to 0.36$])$ between the predicted and observed PF from the force platform and an adjusted $R^{2}(79.6 \%)$ that represented a shrinkage of $0.4 \%$ relative to the cross-validation model $(80 \%$, Table 3$)$. Therefore, the predictive power of the model was not substantially changed when applied to a different sample.

The overall regression model (Table 4) revealed that $\mathrm{PF}$ measured on the dynamometer explained $84.2 \%$ of the variance 
Table 1 Concurrent Validity of the Dynamometer Against the Force Platform for Measuring Peak Force

\begin{tabular}{llllll}
\hline & Dynamometer & Force platform & 95\% LoA & CV\% & Pearson $\boldsymbol{r}$ \\
\hline Peak force $(\mathrm{N})$ & $2041.0 \pm 367.5 *$ & $2254.5 \pm 435.5$ & $-213.5 \pm 342.6$ & 19.3 & .92 \\
\hline Abbreviations: LoA, limits of agreement; CV\%, coefficient of variation. \\
*Significantly lower $(P<.05)$ than peak force derived from force platform.
\end{tabular}

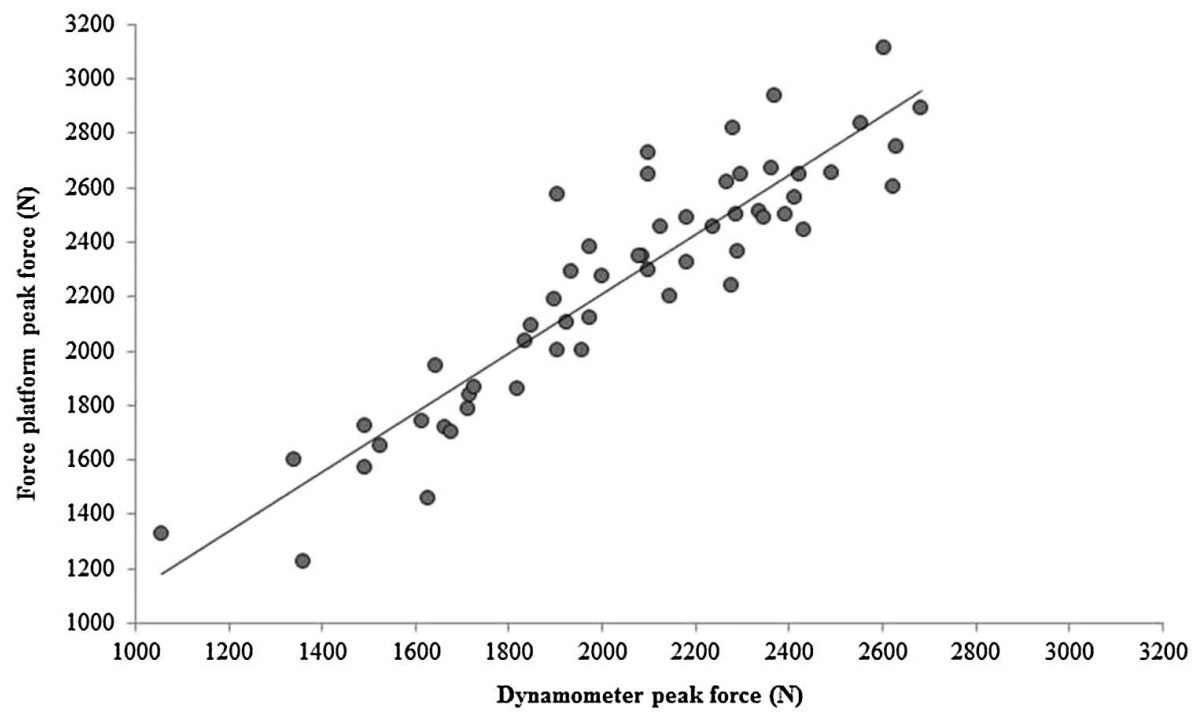

Figure 2 - Relationship between the dynamometer and force platform for measuring peak force.

Table 2 Overall Parameters of the Cross-Validation Prediction Model Using the Dynamometer to Estimate Peak Force Derived From the Force Platform $(n=45)$

\begin{tabular}{|c|c|c|c|c|}
\hline \multirow[b]{2}{*}{ Predictor variable } & \multicolumn{2}{|c|}{ Unstandardized Coefficient } & \multicolumn{2}{|c|}{ Standardized Coefficient } \\
\hline & $B$ & Standard error & Beta & $t$ \\
\hline Constant & 117.594 & 161.600 & & 0.0728 \\
\hline Dynamometer peak force $(\mathrm{N})$ & 1.046 & 0.079 & 0.897 & $13.302 * *$ \\
\hline
\end{tabular}

Note. Adjusted $R^{2}=.800$.

$* * P<.001$.

Table 3 Cross-Validation of Predicted and Observed Force-Platform Peak Force $(n=11)$

\begin{tabular}{cccccc}
\hline & Predicted & Force platform & 95\% LoA & CV\% & Adjusted $\boldsymbol{R}^{\mathbf{2}}$ \\
\hline Peak force $(\mathrm{N})$ & $2344.3 \pm 319.6$ & $2362.8 \pm 388.0$ & $-4.60 \pm 352.56$ & 14.73 & 0.796 \\
\hline
\end{tabular}

Abbreviations: LoA, limits of agreement; CV, coefficient of variation.

Note: Predicted force-platform peak force $=(1.046 \times$ dynamometer peak force $)+117.594$.

Table 4 Overall Parameters for the Prediction Model Using Peak Force Derived From the Dynamometer to Estimate Force-Platform Peak Force $(\mathrm{N}=56)$

\begin{tabular}{lccccc}
\hline & \multicolumn{2}{c}{ Unstandardized Coefficient } & & \multicolumn{2}{c}{ Standardized Coefficient } \\
\cline { 2 - 3 } Predictor variable & $\boldsymbol{B}$ & Standard error & & Beta & $\boldsymbol{t}$ \\
\hline Constant & 31.950 & 131.816 & & 0.242 \\
Dynamometer peak force $(\mathrm{N})$ & 1.089 & 0.064 & & 0.919 & $17.127^{* *}$ \\
\hline
\end{tabular}

Note. Adjusted $R^{2}=.842$.

$* * P<.001$. 
in the dependent variable $(\mathrm{SEE}=173 \mathrm{~N})$. The equation was $\mathrm{PF}(\mathrm{N})=(1.089 \times$ dynamometer $\mathrm{PF})+31.95$.

$\mathrm{PF}$ was greater for the senior than for the youth professionals using both the force plate $(2532.7 \pm 242.5$ cf. $1855.3 \pm 325.1 \mathrm{~N}$, respectively; $t=8.93, P<.001, \mathrm{ES}=2.36$ [1.96-2.76]) and the modified dynamometer $(2261.2 \pm 222.0 \mathrm{cf}$. $1725.1 \pm 298.0 \mathrm{~N}$, respectively; $t=7.66, P<.001$, ES $=2.04$ [1.66-2.42]). Due to the large difference in body mass (ES 1.32 [0.98-1.66]), PF data were scaled to account for this difference. Senior players generated significantly greater force than youth players with both ratio $(26.07 \pm 3.08$ cf $21.58 \pm 3.71 \mathrm{~N} / \mathrm{kg}, t=4.936, P<.001, \quad \mathrm{ES}=$ $1.32[0.98-1.66])$ and allometric scaling (23.44 $\pm 2.63 \mathrm{cf}$ $19.46 \pm 3.35 \mathrm{~N} / \mathrm{kg}^{1.02}, t=4.828, P<.001, \mathrm{ES}=1.32[0.98-1.66]$ ) applied. Similarly, PF was greater for the senior players than for the youth on the dynamometer for ratio $(23.25 \pm 2.63 \mathrm{cf} 20.04 \pm$ $3.25 \mathrm{~N} / \mathrm{kg}, t=4.069, P<.001, \mathrm{ES}=1.09$ [0.76-1.42]) and allometrically $\left(21.88 \pm 2.50 \mathrm{cf} 18.89 \pm 3.07 \mathrm{~N} / \mathrm{kg}^{1.01}, t=4.01, P<.001\right.$, $\mathrm{ES}=1.07[0.74-1.40])$ scaled values.

\section{Discussion}

This study sought to compare the PF obtained during the isometric midthigh pull performed on a customized dynamometer and a force platform in a group of professional rugby league players (ie criterion validity). Additionally, comparisons between 2 playing standards (senior and junior professionals) were made to determine the construct validity of the isometric midthigh pull for use with rugby league players. The principal finding of this study was that the isometric midthigh pull performed on a custom-built dynamometer underestimated PF from a force platform, as evidenced by the significant difference and small effect size. However, there was a strong relative agreement between both measurement methods. As such, a regression equation was developed that could correct this "average" underestimation. Finally, the modified dynamometer was able to differentiate PF between playing standards, suggesting that it possesses appropriate construct validity in the measurement of muscle-function characteristics of senior and youth professional rugby league players.

There was poor agreement between PF measurements during an isometric midthigh pull on the modified dynamometer and the force platform. The mean difference in PF achieved between the 2 methods indicated that the modified dynamometer was, on average, $-213.5 \mathrm{~N}$ lower than the force platform. This is consistent with the systematic bias $(-229.1 \mathrm{~N})$ between similar apparatuses reported by James et al. ${ }^{18}$ When the $95 \%$ LoA were considered, a player with a PF of $2000 \mathrm{~N}$ measured during an isometric midthigh pull using a force platform could, in the worst-case scenario, achieve a value between 1444 and $2129 \mathrm{~N}$ using the modified dynamometer. To provide context, this potential error $(\sim 685 \mathrm{~N})$ is larger than improvements in PF derived from an isometric midthigh pull after a 9-week maximal-strength or power-training program $\left(431-608 \mathrm{~N}^{29}\right)$. This means it would be difficult to detect meaningful changes in midthigh-pull performance when using the modified dynamometer, and, therefore, when small to moderate changes are expected, practitioners might consider using a regression equation or force platform.

The underestimation in PF observed in the present study might be explained by the more open-chain design of the modified dynamometer compared with that of the force platform. During the force-platform trials, peak ground-reaction force was measured through the feet in contact with the force platform and force applied vertically in a single plane. In contrast, the modified dynamometer required participants to pull vertically on a bar anchored centrally, which due to its design had a large degree of anteroposterior and mediolateral movement. It is possible that this movement allowed participants to lean back into the pull, resulting in force being applied outside of the vertical axis. ${ }^{18}$ It is also possible that the superior sampling frequency of the force platform compared with the modified dynamometer (1200 cf $122 \mathrm{~Hz}$, respectively) influenced the precision of the PF measurements. ${ }^{14}$

To correct for the underestimation of PF using the modified dynamometer, we developed a regression equation that reduces the difference from the force platform to within mean values of $\sim 4.6 \mathrm{~N}$. Therefore, when a comparison between methods is necessary, this equation can be applied to data collected from the modified dynamometer when using a sample similar to that used in this study. However, practitioners should note that there might be some error in this estimate of $\sim 173 \mathrm{~N}$ in individual cases, owing to the fact that some of the variance in force-platform performance was not explained by performance using the modified dynamometer.

In this study, players of a higher standard, who are deemed to be stronger from more extensive resistance-training exposure ${ }^{6}$ performed better on the isometric midthigh pull using both methods. More specifically, PF measured on the modified dynamometer for senior professional rugby league players was $31 \%$ higher than that of youth professionals, similar to the difference of $\sim 36 \%$ according to the force platform. Furthermore, our results indicate that this large difference in PF was irrespective of differences in body mass. After applying both ratio and allometric scaling, the results indicated that senior players outperformed youth players regardless of body mass, suggesting that training history is an important factor when assessing PF. As such, the modifieddynamometer midthigh pull is sufficiently sensitive to be used to classify the strength capabilities of professional rugby league players of different standards and training histories.

\section{Practical Applications}

A criterion measure of PF during an isometric midthigh pull cannot be measured from a modified dynamometer. This notwithstanding, the dynamometer is capable of distinguishing differences in muscle function between more- and less-experienced rugby league players. For practitioners who require more-accurate measures of $\mathrm{PF}$ from isometric midthigh pull, they might choose to use the regression equation provided. It is important to note that the prediction equation for PF is specific to rugby league players, and caution should be taken when applying this to other populations. Strength and conditioning coaches who wish to measure maximal strength when profiling rugby players might adopt this safe, cost-effective, and valid apparatus.

\section{Conclusion}

The current study investigated the criterion and construct validity of a modified dynamometer for the assessment of isometric midthigh-pull strength. Where practitioners are required to profile players (ie, talent identification), a modified dynamometer can be used to differentiate between academy and first-grade professional rugby league players. In addition, the regression equation provided can allow practitioners to detect training-induced changes in whole-body strength, but they should be cognizant that small changes are likely to go undetected, and in such cases, a force platform should be used. 


\section{References}

1. Comfort P, Haigh A, Matthews MJ. Are changes in maximal squat strength during preseason training reflected in changes in sprint performance in rugby league players? J Strength Cond Res. 2012;26(3): 772-776. PubMed doi:10.1519/JSC.0b013e31822a5cbf

2. Speranza MJ, Gabbett TJ, Johnston RD, Sheppard JM. Muscular strength and power correlates of tackling ability in semiprofessional rugby league players. J Strength Cond Res. 2015;29(8):2071-2078. PubMed doi:10.1519/JSC.0000000000000897

3. Suchomel TJ, Nimphius S, Stone MH. The importance of muscular strength in athletic performance. Sports Med. 2016;46(10):1419-1449. PubMed doi:10.1007/s40279-016-0486-0

4. Gabbett TJ, Ullah S, Finch CF. Identifying risk factors for contact injury in professional rugby league players - application of a frailty model for recurrent injury. J Sci Med Sport. 2012;15(6):496-504. PubMed doi:10.1016/j.jsams.2012.03.017

5. Baker DG, Newton RU. Comparison of lower body strength, power, acceleration, speed, agility, and sprint momentum to describe and compare playing rank among professional rugby league players. J Strength Cond Res. 2008;22(1):153-158. PubMed doi:10.1519/ JSC.0b013e31815f9519

6. Till K, Jones B, Geeson-Brown T. Do physical qualities influence the attainment of professional status within elite 16-19 year old rugby league players? J Sci Med Sport. 2016;19(7):585-589. PubMed doi:10.1016/j.jsams.2015.07.001

7. Darrall-Jones JD, Jones B, Till K. Anthropometric and physical profiles of english academy rugby union players. J Strength Cond Res. 2015;29(8):2086-2096. PubMed doi:10.1519/JSC.000000000 0000872

8. Meylan CM, Cronin JB, Oliver JL, Hughes MM, Jidovtseff B, Pinder $\mathrm{S}$. The reliability of isoinertial force-velocity-power profiling and maximal strength assessment in youth. Sports Biomech. 2015;14(1): 68-80. PubMed doi:10.1080/14763141.2014.982696

9. Abernethy P, Wilson G, Logan P. Strength and power assessment: issues, controversies and challenges. Sports Med. 1995;19(6): 401-417. PubMed doi:10.2165/00007256-199519060-00004

10. Myer GD, Quatman CE, Khoury J, Wall EJ, Hewett TE. Youth versus adult "weightlifting" injuries presenting to United States emergency rooms: accidental versus nonaccidental injury mechanisms. J Strength Cond Res. 2009;23(7):2054-2060. PubMed doi:10.1519/ JSC.0b013e3181b86712

11. McGuigan MR, Winchester JB. The relationship between isometric and dynamic strength in college football players. J Sports Sci Med. 2008;7(1):101-105. PubMed doi:10.1249/01.mss.0000322664. 81874.75

12. McGuigan MR, Newton MJ, Winchester JB, Nelson AG. Relationship between isometric and dynamic strength in recreationally trained men. J Strength Cond Res. 2010;24(9):2570-2573. PubMed doi:10.1519/JSC.0b013e3181ecd381

13. Crewther BT, Kilduff LP, Cook CJ, et al. Relationships between salivary free testosterone and the expression of force and power in elite athletes. J Sports Med Phys Fitness. 2012;52(2):221-227. PubMed
14. Dos'santos T, Jones PA, Kelly J, McMahon JJ, Comfort P, Thomas C. Effect of sampling frequency on isometric midthigh-pull kinetics. Int J Sports Physiol Perform. 2016;11(2):255-260. PubMed doi:10. 1123/ijspp.2015-0222

15. West DJ, Owen NJ, Jones MR, et al. Relationships between force-time characteristics of the isometric midthigh pull and dynamic performance in professional rugby league players. $J$ Strength Cond Res. 2011;25(11):3070-3075. PubMed doi:10.1519/JSC. 0b013e318212dcd5

16. McMaster DT, Gill N, Cronin J, McGuigan M. A brief review of strength and ballistic assessment methodologies in sport. Sports Med. 2014;44(5):603-623. PubMed doi:10.1007/s40279-014-0145-2

17. De Witt JK, English KL, Crowell JB, et al. Isometric mid-thigh pull reliability and relationship to deadlift 1RM. J Strength Cond Res. 2016. PubMed doi:10.1519/JSC.0000000000001605

18. James LP, Roberst LA, Haff GG, Kelly VG, Beckman EM. The validity and reliability of a portable isometric mid-thigh clean pull. J Strength Cond Res. 2017;31(5):1378-1386. PubMed doi:10.1519/ JSC.0000000000001201

19. Haugen T, Buchheit M. Sprint running performance monitoring: methodological and practical considerations. Sports Med. 2016; 46(5):641-656. PubMed doi:10.1007/s40279-015-0446-0

20. Baumgarter TA, Jackson AS. Measurement for Evaluation in Physical Education and Exercise Science. Dubuque, IA: Wm C Brown; 1987.

21. Dos'santos T, Thomas C, Comfort P, et al. Between-session reliability of isometric mid-thigh pull kinetics and maximal power clean performance in male youth soccer players. J Strength Cond Res. 2017. PubMed doi:10.1519/JSC.0000000000001830

22. Thomas C, Jones PA, Rothwell J, Chiang CY, Comfort P. An investigation into the relationship between maximum isometric strength and vertical jump performance. J Strength Cond Res. 2015;29(8): 2176-2185. PubMed doi:10.1519/JSC.0000000000000866

23. Beckham G, Mizuguchi S, Carter C, et al. Relationships of isometric mid-thigh pull variables to weightlifting performance. J Sports Med Phys Fitness. 2013;53(5):573-581. PubMed

24. Bland MJ, Altman DG. Statistic methods for measuring agreement of clinical measurement. Lancet. 1986;327(8476):307-310. PubMed doi:10.1016/S0140-6736(86)90837-8

25. Hopkins WG, Marshall SW, Batterham AM, Hanin J. Progressive statistics for studies in sports medicine and exercise science. Med Sci Sports Exerc. 2009;41(1):3-13. PubMed doi:10.1249/MSS. 0b013e31818cb278

26. Field A. Discovering Statistics Using IBM SPSS Statistics: And Sex and Drugs and Rock ' $n$ ' Roll. 4th ed. London, UK: Sage; 2013.

27. Crewther BT, Gill N, Weatherby RP, Lowe T. A comparison of ratio and allometric scaling methods for normalizing power and strength in elite rugby union players. J Sports Sci. 2009;27(14):1575-1580. PubMed doi:10.1080/02640410903348657

28. Hopkins WG. Spreadsheets for analysis of controlled trials with adjustment for a subject characteristic. Sportscience. 2006;10:46-50.

29. Harris GR, Stone MH, O'Bryant HS, Proulx CM, Johnson RL. Shortterm performance effects of high power, high force, or combined weight-training methods. J Strength Cond Res. 2000;14(1):14-20. doi:10.1519/1533-4287(2000)014<0014:STPEOH>2.0.CO;2 
Copyright of International Journal of Sports Physiology \& Performance is the property of Human Kinetics Publishers, Inc. and its content may not be copied or emailed to multiple sites or posted to a listserv without the copyright holder's express written permission. However, users may print, download, or email articles for individual use. 